\title{
Pregnancy-related cervical cancer in the material of the Regional Cancer Centre, Łódź, between 2011 and 2014
}

\author{
Justyna Danielska ${ }^{1}$, Małgorzata Moszyńska-Zielińska ${ }^{1}$, Leszek Gottwald ${ }^{1}$, \\ Miłosz Wilczyński ${ }^{2}$, Jacek R. Wilczyński ${ }^{3}$, Jacek Fijuth ${ }^{1}$
}

Introduction. Pregnancy-related cancer is defined as cancer diagnosed during pregnancy or in the first postpartum year. Cervical cancer affects approximately 1 in 1000 pregnant women and is the most common malignancy affecting pregnancy. We retrospectively analysed the clinical outcome and results of treatment in patients with pregnancy-related cervical cancer.

Material and methods. We retrospectively analysed the medical records of nine patients with invasive cervical cancer diagnosed during pregnancy and the postpartum period who had been treated in the Regional Oncological Centre, Łódź, between 2011-2014.

Results. Three patients with cervical cancer at stage I were diagnosed between the $14^{\text {th }}$ and $17^{\text {th }}$ week of pregnancy afterwards and underwent radical surgery. Two patients with cervical cancer at stage lb who were diagnosed in the $19^{\text {th }}$ and $24^{\text {th }}$ week of gestation decided to continue pregnancy until the $30^{\text {th }}$ and $32^{\text {nd }}$ week; then a cesarean section combined with radical surgery was performed. In three patients with inoperative cervical cancer diagnosed between the $26^{\text {th }}$ and $28^{\text {th }}$ week of pregnancy, a cesarean section was performed at week 30-32. In one patient cervical cancer at stage Ilb was diagnosed during the post-partum period. All patients were treated using intensity-modulated radiotherapy (IMRT) to a total dose of $44 \mathrm{~Gy} / 2 \mathrm{~Gy}$, weekly cisplatin $\left(40 \mathrm{mg} / \mathrm{m}^{2}\right)$ concurrent with radiotherapy and brachytherapy. No toxicity was observed. During follow-up, two patients with inoperable cervical cancer were diagnosed with a recurrence 2 and 10 months after treatment, respectively.

Conclusions. The management of pregnancy-related cervical cancer is mainly determined by the week of the pregnancy and the stage of the disease at diagnosis, but also by the patient choice. The general condition and follow-up of newborns from pregnancies complicated by cervical cancer are similar to those of newborns arising from non-complicated pregnancies. Treatment toxicity is similar in cases with pregnancy-related cervical cancer and in non-pregnant women with cervical cancer. The major prognostic factor in pregnancy-related cervical cancer remains the stage of the disease at diagnosis.

NOWOTWORY J Oncol 2016; 66, 5: 359-366

Key words: cervical cancer, pregnancy, radiotherapy, brachytherapy, radical hysterectomy

\section{Introduction}

Pregnancy-related cancer is defined as cancer diagnosed during pregnancy or in the first postpartum year [1-3]. With regards to changes of lifestyle of women in recent years and the conscious decision to delay procreation, the frequency of malignant tumours occurring simultaneously with pregnancy is growing. The most frequently diagnosed cancers among pregnant and post-partum women are: cervical cancer, breast cancer, melanoma, lymphoma and, to a lesser degree, leukaemia [4-6].

\footnotetext{
${ }^{1}$ Department of Radiotherapy, Medical University of Lódź, Lódź, Poland

${ }^{2}$ Department of Surgical, Endoscopic and Oncologic Gynecology, Polish Mother's Memorial Hospital Research Institute, Lódź, Poland
}

${ }^{3}$ Gynecology and Gynecologic Oncology Department, Polish Mother’s Memorial Hospital Research Institute, Łódź, Poland 


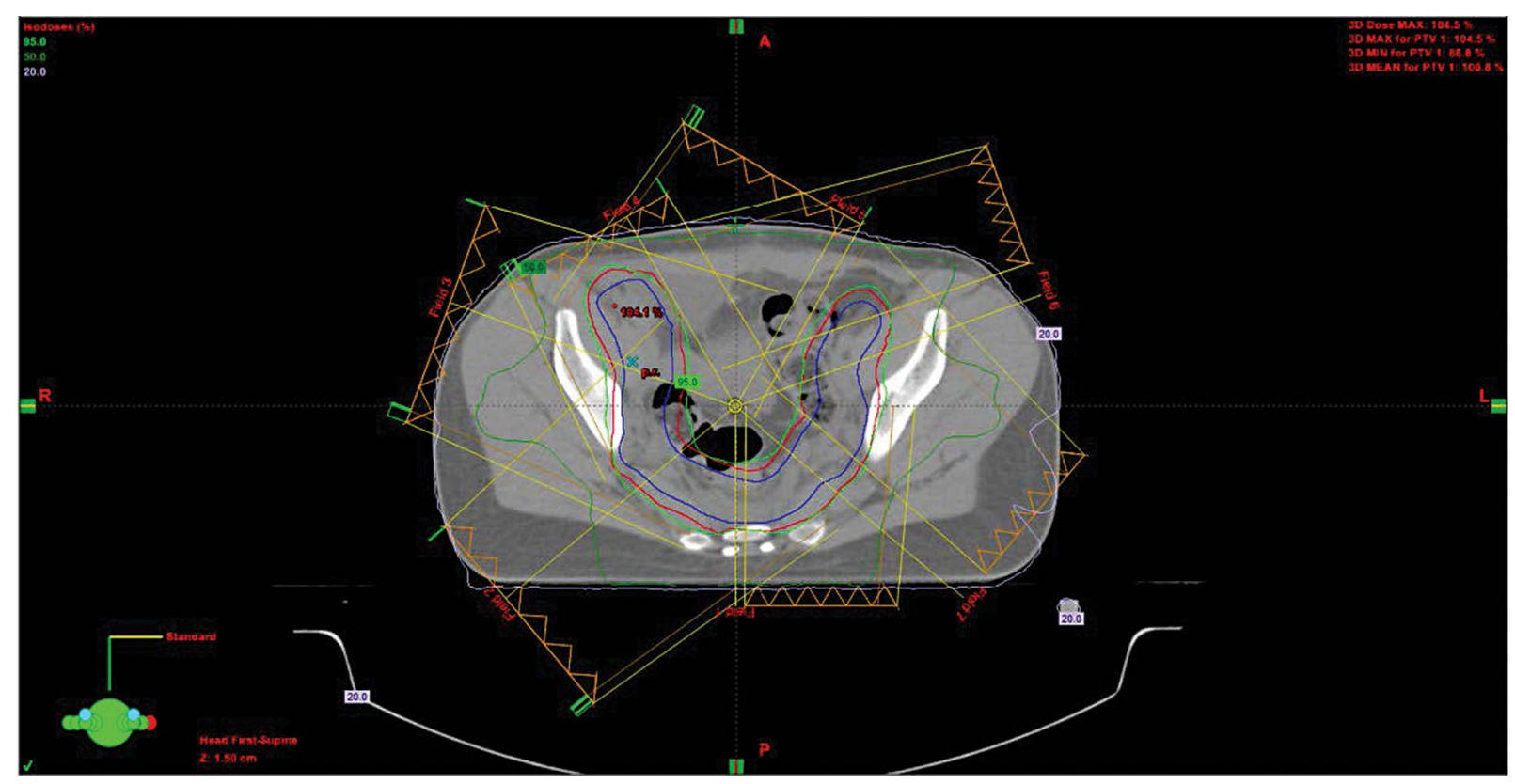

Figure 1. Radiotherapy planning in patient with non-resectable cervical cancer - IMPR technique

The incidence of cervical cancer ranks second after breast cancer in the world population of women with peak mortality in the peri-menopausal period. However, in Poland, about $1 / 3$ of all cases of this cancer are diagnosed in women in the procreative age. As the data of the National Cancer Register shows, in Poland the prevalence of cervical cancer has been decreasing since the mid-1980s, with 2909 new cases and 1669 deaths from malignant tumours in this location, registered in 2013 [7]. Almost 3\% of cases of cervical cancer occur during pregnancy and in the post-partum period and the frequency of diagnosing cervical cancer in pregnancy is 1:1000 pregnancies [8-12]. The average age of women with cervical cancer diagnosed in pregnancy is 31 years. It is believed that thanks to frequent obstetrical examinations during pregnancy, the possibility of diagnosing cervical cancer in pregnant women is three times greater than in the case of non-pregnant women [13].

The objective of this study was to perform clinical analysis and the evaluation of treatment results in patients with pregnancy-related cervical cancer, treated in the Regional Oncological Centre, Łódź, in 2011-2014.

\section{Materials and methods}

The medical files of patients treated at the Department of Tele-radiotherapy of N. Copernicus Voivodeship Specialist Hospital in Łódź, treated in 2011-2014 were analysed. There were 9 patients with histopathologically confirmed cervical cancer diagnosed during pregnancy or the post-partum period. The advancement stage of the cancers was evaluated according to FIGO classification (International Federation of Gynaecology and Obstetrics). The treatment of all patients consisted of tele-radiotherapy in connection with cisplatin (radio-chemotherapy) and brachytherapy.

The patients received conformal IMRT tele-radiotherapy up to $44 \mathrm{~Gy}$ in 22 fractions of $2 \mathrm{~Gy}$ ( 5 fractions per week with a two-day break) in connection with cisplatin injections with a dose of $40 \mathrm{mg} / \mathrm{m}^{2}$ once per week with adjuvant treatment (Figs. 1, 2). The process of planning conformal radiotherapy consisted of rendering planar computed tomography images and planning the dose distribution in target volumes with the three-dimensional technique. The clinical target volume (CTV), in the case of post-surgery patients comprised the tumour bed left after the excised reproductive organ as well as regional lymph nodes: common iliac, external and internal, obturator and presacral lymph nodes. In non-surgical cases, the CTV area comprised the tumour-infiltrated uterine cervix and body, vaginal walls and fornix, parametria and regional lymph nodes.

Tele-radiotherapy was combined with high dose radiotherapy (HDR), with the system after loading, consisting in the remote implantation of radioactive substances on the guides located in the reproductive organ. The irradiation source was iridium 192. Intracavitary applications were performed with the use of intravaginal applicators and uterine probes. The diameter of cylindrical applicators was adapted to the anatomic conditions (cylinders with the diameter of $2.5-4.0 \mathrm{~cm}$ ). Brachytherapy planning and applicators placement verification was made with the assistance of computed tomography paired with the computed system of calculating the distribution of irradiation dosage.

The clinical parameters, the course of treatment and its results were analysed. In the study group, the analysed 


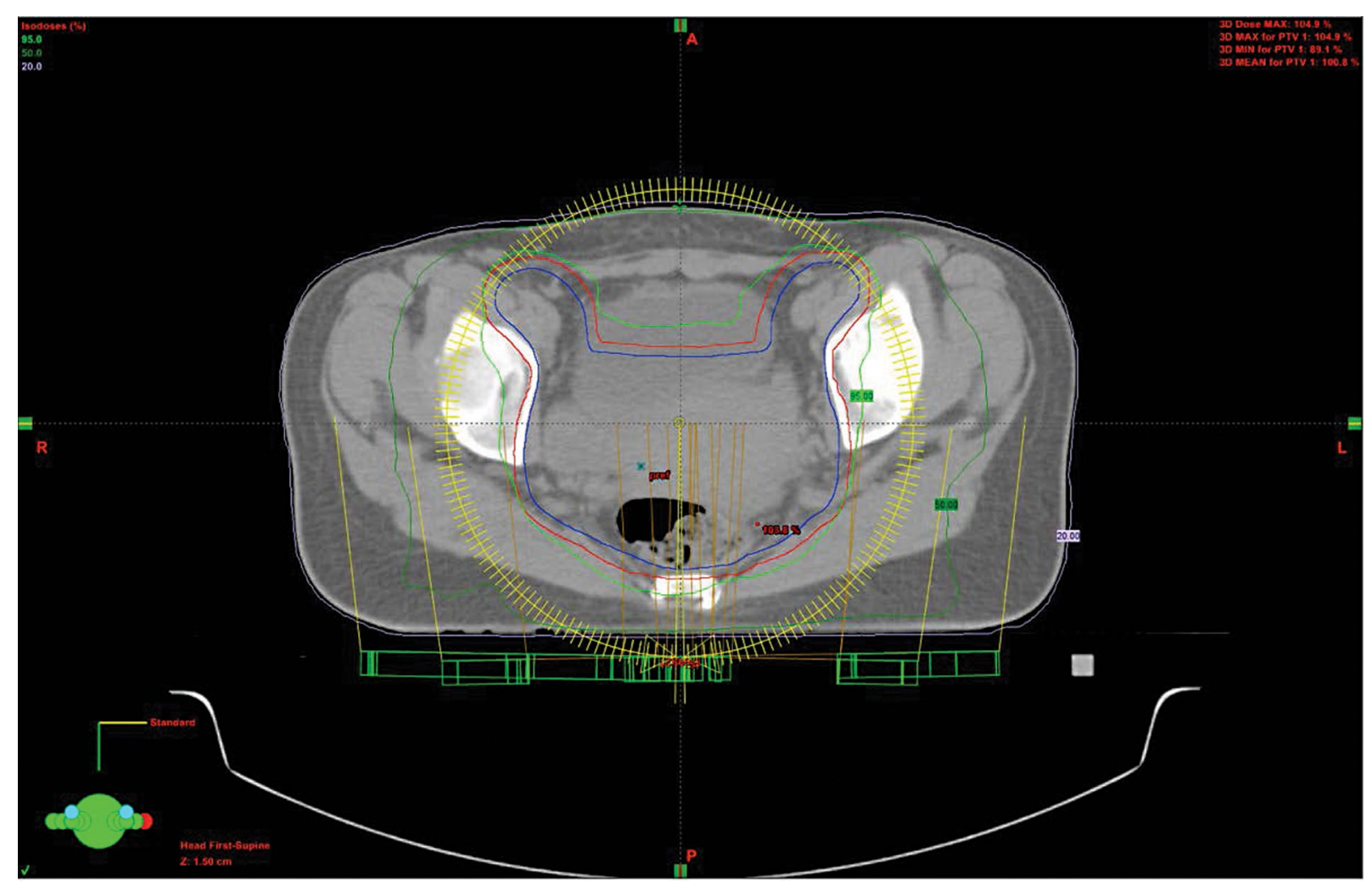

Figure 2. Radiotherapy planning in patient with non-resectable cervical cancer — VMAT Volumetric Modulated Arc Therapy) technique

parameters were the age of the patients, the course of pregnancy, type of delivery and obstetric results as well as the tolerance and the results of the oncological treatment. The intensity of irradiation reactions was evaluated with the RTOG/EORTC scale (Radiation Therapy Oncology Group/European Organization for Research and Treatment of Cancer).

\section{Results}

Cervical cancer was diagnosed in eight pregnant patients in the $2^{\text {nd }}$ and $3^{\text {rd }}$ trimester of gestation, and in one case - during the post-partum period. The clinical characteristics of the study group is presented in Table I. The treatment protocols were varied depending on the clinical situation of the patient. Before the commencement of the treatment, all the patients were informed in detail about their clinical situation and gave their consent for the proposed method of treatment.

In five cases, cervical cancer was diagnosed in the second trimester of gestation - in gestation week 14, 14, 17, 19 and 24 respectively. In three patients, cervical cancer was diagnosed in its second stage of clinical advancement, between the $14^{\text {th }}$ and $17^{\text {th }}$ gestation week, and Wertheim-Meigs surgery was performed. Two other patients with cervical cancer, stage: IB, diagnosed in gestation week 19 and 24 ( $2^{\text {nd }}$ trimester), continued pregnancy till gestation week 30 and 32. During that period they received no oncological treatment. After the assessment of lung maturity in the foetuses, the patients underwent caesarean section together with Wertheim-Meigs surgery (Figs. 3, 4). In three other patients, cervical cancer was diagnosed in the third trimester, between gestation week 26 and 28. These gestations were continued with no oncological treatment till week 30-32 and then a caesarean section was performed after the previous assessment of the foetal lung maturity. In three cases, the cancer development stage (IIB, IIIA, IIIB) made radical surgery impossible. In one patient who gave birth to a healthy child, cervical cancer was diagnosed in the post-partum period. All the five infants born by caesarean section, between gestation week 30 and 32 , survived. There were no adaptation complications observed in the infants born from the pregnancies with cervical cancer in the mothers. The infants, after the end of the adaptation period, were discharged from the neonatology ward in good shape.

The treatment in the surgical ward was carried out according to the above described protocol. No significant complications were observed in the course of the treatment. After treatment completion, the patients went through a follow-up in an outpatient unit of the oncology centre. The specific data concerning the follow-up period in specific cases is presented in Table 1. In two patients, cancer recurrence was diagnosed 2 and 10 months after treatment completion. The patient, in whom distant metastases were diagnosed in the lungs and liver, died within 8 weeks of the diagnosis of the primary cervical cancer. In the second 


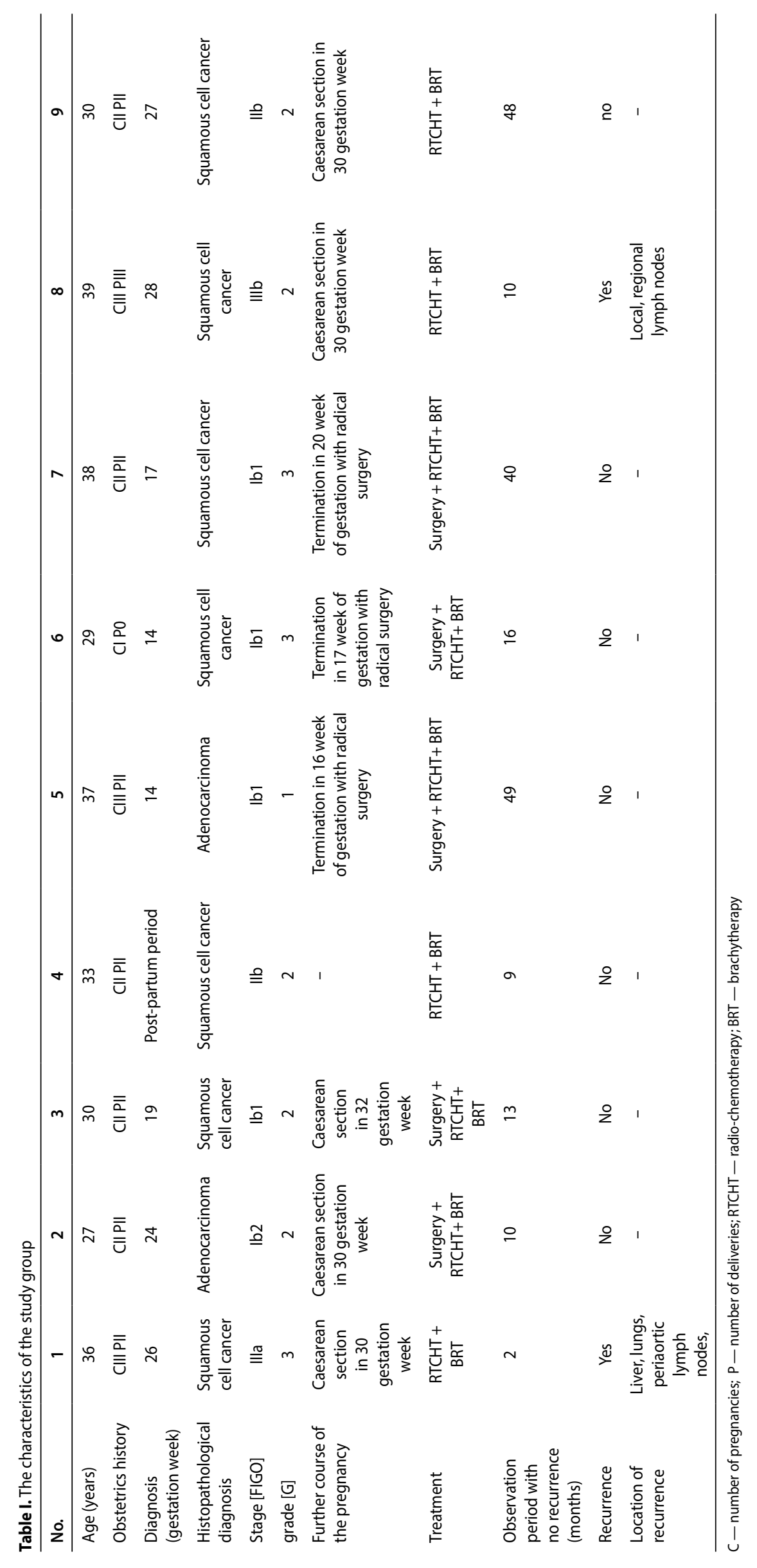




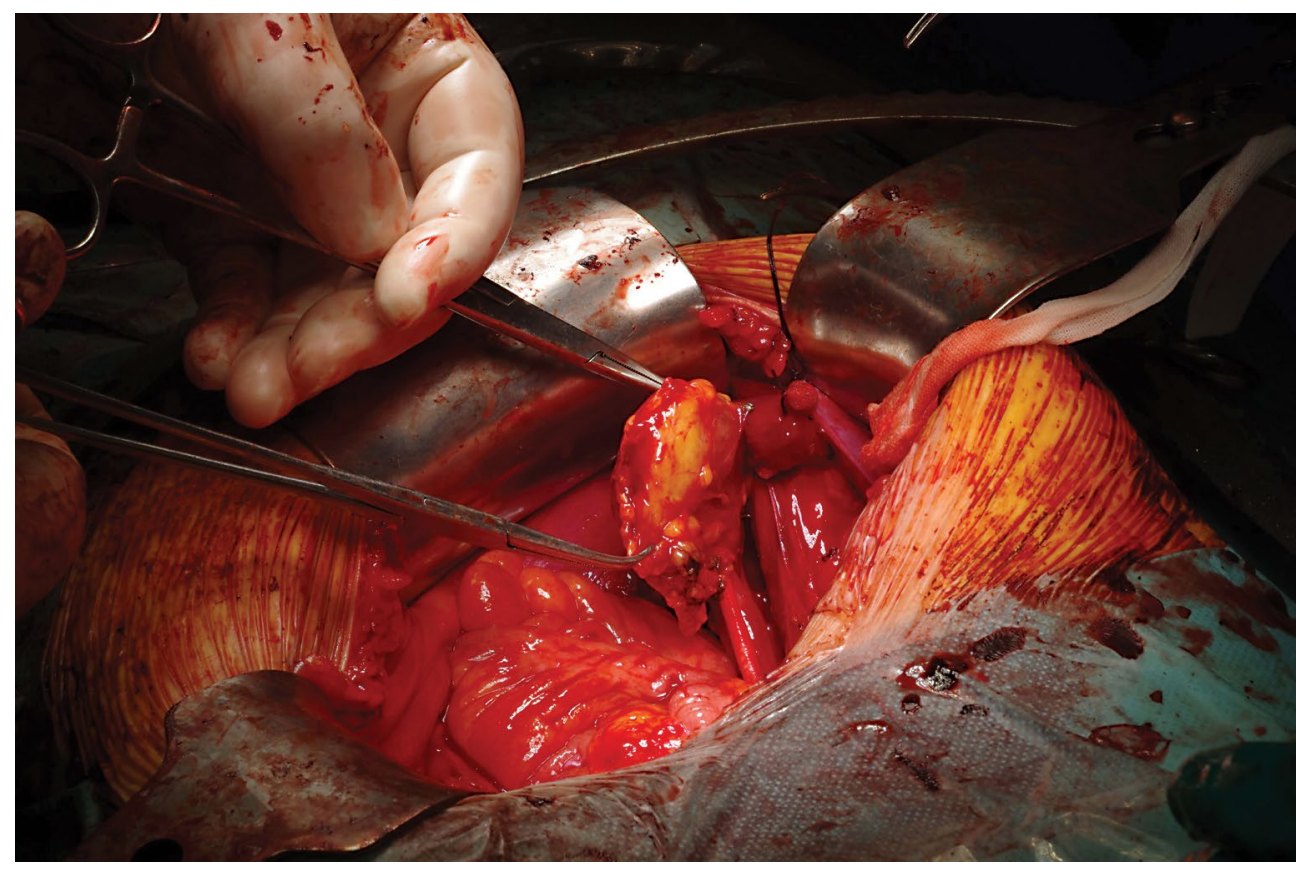

Figure 3. Pelvic lymphadenectomy during radical surgery for cervical cancer

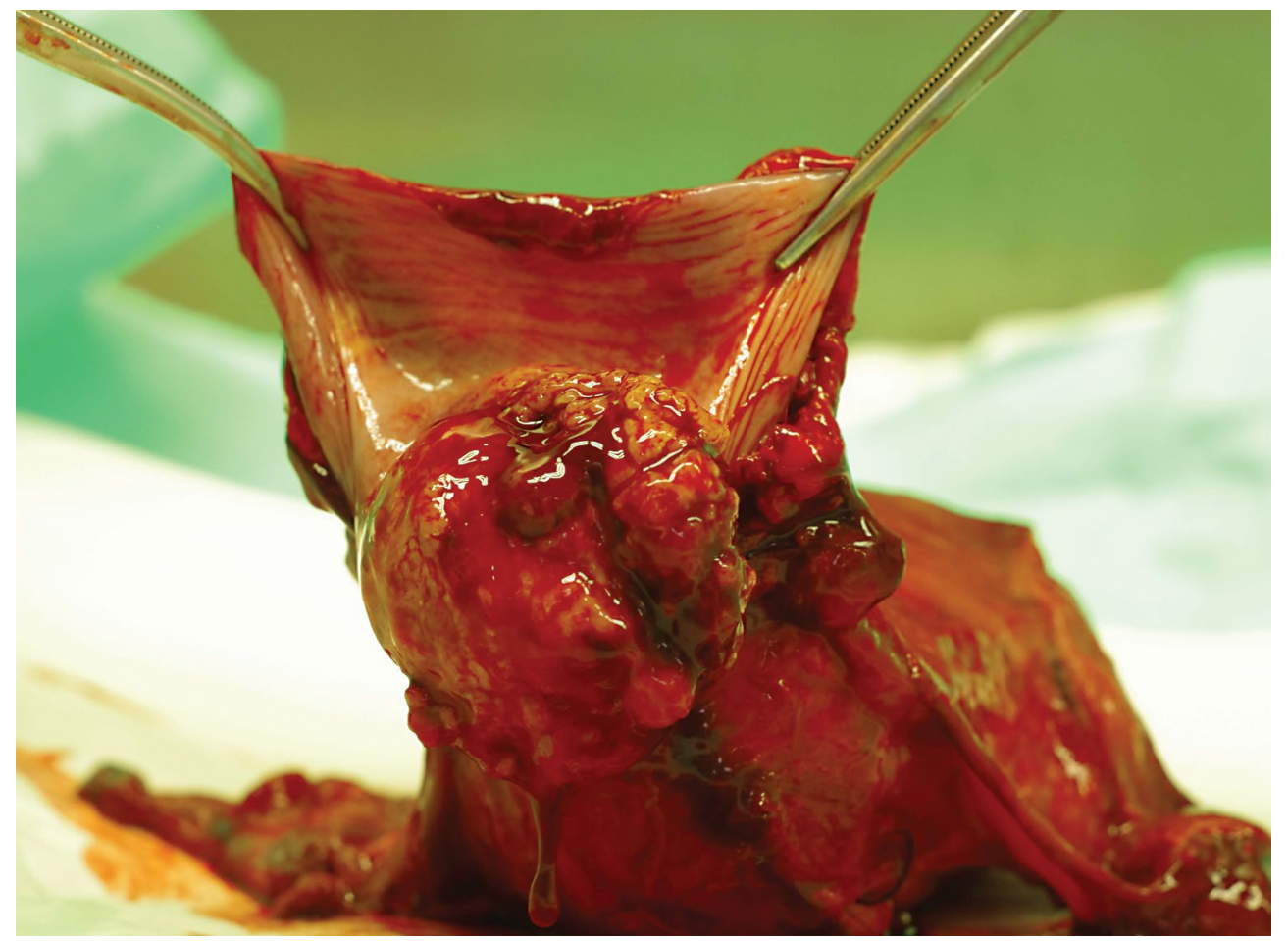

Figure 4. Exophytic cervical cancer - post-surgical specimen

patient, palliative treatment was applied. Currently, her neoplastic process has been stabilised.

During the radiotherapy, the intensification of an early post-irradiation reaction was evaluated in the RTOG scale every 7 days. During the oncological treatment, in two patients, some post-irradiation grade I and II reactions were found in the area of the anus and the urinary bladder. No grade III or IV reactions were found. 


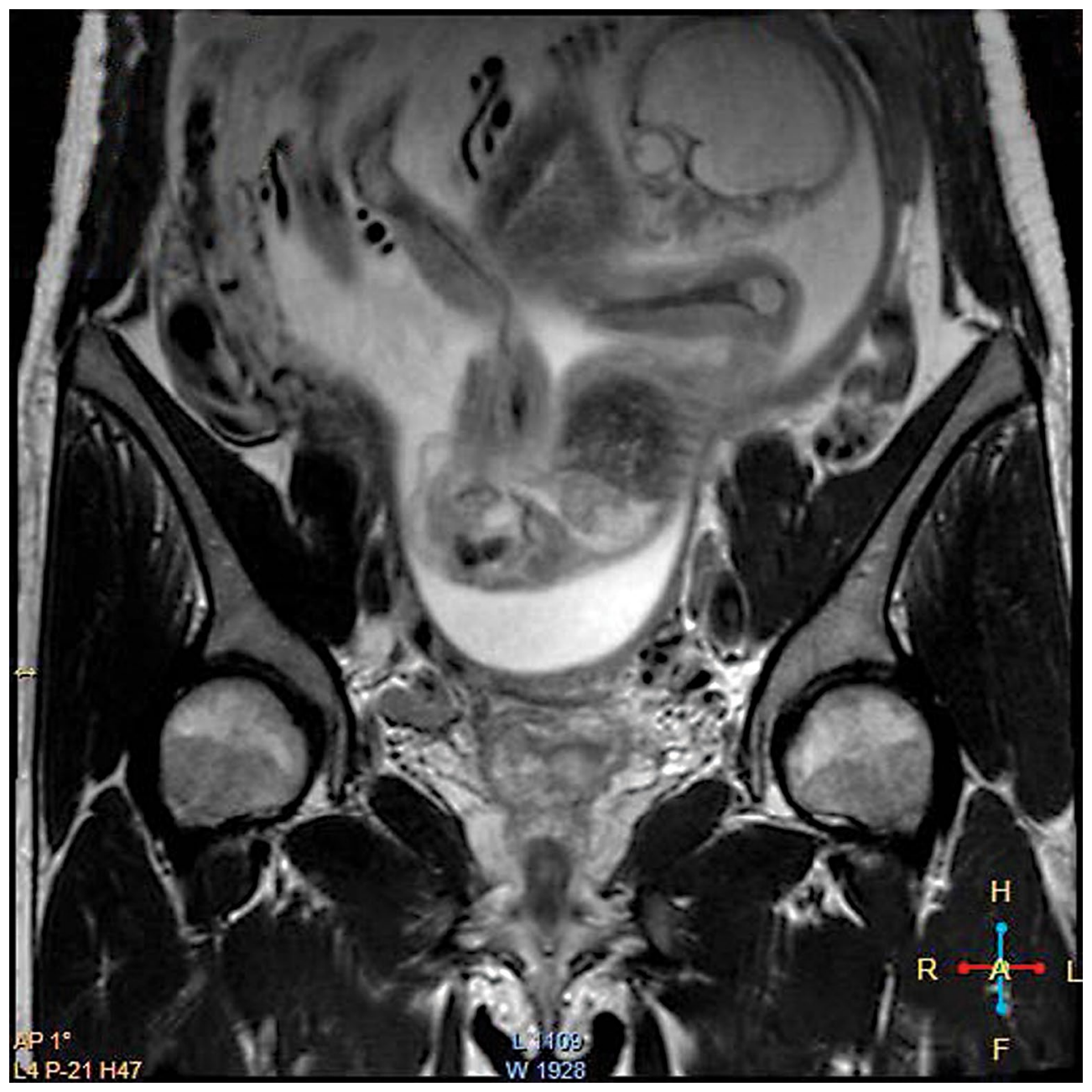

Figure 5. Cervical cancer in a pregnant women in $3^{\text {rd }}$ trimester - NMR imaging

\section{Discussion}

The publications present contradictory opinions concerning the effect of pregnancy on the biology of cervical cancer. Some potential factors modifying the course of oncological disease in pregnant patients are increased perfusion and lymphatic drainage of the organs, hormonal factors and immunomodulation. In the opinion of some investigators, immunosuppression during pregnancy might foster the dissemination of cancer, whist other authors in turn, believe that pregnancy does not affect the course of cancer in any significant way [14]. There is no convincing evidence concerning the course of cervical cancer in pregnancy, so it seems highly necessary to continue research in this respect [15-17].

The cancer development stage and the period of pregnancy are of key significance for the choice of optimal therapeutic treatment [18]. The core examination necessary for the evaluation of the local development stage of the cancer in a precise way is nuclear magnetic resonance imaging (NMR) (Fig. 5) [19]. A detailed evaluation of the lymphatic system of the abdomen paired with a clinical assessment of the patient and an NMR examination allows one to establish the optimal pattern of treatment. In pregnant patients, CT is not performed unless there are life-threatening issues [20].

Another factor affecting the choice of the treatment strategy is the period of gestation in which the cervical cancer is diagnosed [21]. If the diagnosis is made in the first two trimesters of gestation, the continuation of pregnancy for many weeks would lead to a significant delay in the commencement of treatment, worsening the prognosis; therefore it is recommended to terminate the pregnancy and commence treatment urgently. Given the immense progress of perinatology, if cervical cancer is diagnosed at the end of the second trimester of gestation (week 23-24), the therapeutic decisions must be individualised and based on the evaluation of the clinical situation and the possibilities of the institution [22]. In the study group, in the cases when cervical cancer was diagnosed in the second trimester, it was decided to terminate the pregnancy and to begin oncological treatment as fast as possible. If the cancer is diagnosed in the third trimester of pregnancy, the gestation is most frequently continued till the moment when 
the foetal maturity allows for the delivery of an infant who is cardiovasculary and respiratorily stable. Then, similarly to the study group, a caesarean section is performed and oncological treatment begins. In the two-above cases of resectable cervical cancers, the caesarean section was combined with radical surgery which is compliant with the binding treatment standards.

The core of radiotherapy of cervical cancer diagnosed in pregnancy lies in the adequate and precise combination of tele-radiotherapy with the injections of platinum compounds and with brachytherapy. According to the recommendations of the American Brachytherapy Society, the total duration of radiotherapy should not exceed 8 weeks [23]. The sequence of application and the size of fractional and therapeutic doses are still disputable and in practice they are individually established. With regards to the manner of fractionation of HDR brachytherapy ( $1 \times$ week), it is really essential to observe the appropriate duration of tele-radiotherapy. The publications on this issue, emphasise the adverse effect of prolonged radiotherapy on prognoses in patients with cervical cancer [24]. As the diagnosis of cervical cancer in pregnancy prolongs the time period till the commencement of radiotherapy, which is prognostically adverse, in advanced stages of cervical cancer, the radio-chemotherapy should be commenced immediately after childbirth.

In pregnant women with cervical cancer, the prognoses are similar to patients who are not pregnant. The cancer stage at the moment of diagnosis is regarded as the core factor which determines the prognosis, which was also confirmed in this study [18, 25-30]. In the study group, cancer recurrence was found in two cases in which cervical cancer was diagnosed in the locally advanced stage of the disease. No recurrence was observed among other patients with resectable surgical cancer. In addition, no relationship was found between the age of the patients and the prognoses. The small number of subjects within the study group, however, does not allow for a generalisation of the results onto the population. With respect to many controversies and doubts connected with the issue of cervical cancer in pregnancy, it is necessary to carry out further research to ensure we gain better knowledge of the biological and pathophysiological mechanisms of this cancer.

\section{Conclusions}

1. The advancement stage of cervical cancer, the period of pregnancy in which the cancer was diagnosed as well as the attitude of the patient being aware of her situation determine the course of action in this group of patients.

2. The general condition and the course of the adaptation period of the infants born from the pregnancies complicated with cervical cancer do not differ from the condition of infants born by healthy mothers in the equivalent gestation weeks.
3. The tolerance of radiotherapy and radio-chemotherapy in post-partum women with cervical cancer diagnosed in pregnancy does not differ from the tolerance of this type of treatment in non-pregnant women with cervical cancer.

4. The core factor which determines the prognoses for patients with cervical cancer remains the cancer advancement stage at the moment of diagnosis.

\section{Conflict of interest: none declared}

\section{Justyna Danielska, MD}

Department of Radiotherapy

Medical University of Łódź

Pabianicka 62, 93-513 Łódź, Poland

e-mail:justyna_danielska@gazeta.pl

Received: 20 Feb 2016

Accepted: 6 Jun 2016

\section{References}

1. Smith LH, Dalrymple JL, Leiserowitz GS et al. Obstetrical deliveries associated with maternal malignancy in California, 1992 through 1997. Am J Obstet Gynecol 2001; 184: 1504-1512.

2. Dahling MT, Xing G, Cress R et al. Pregnancy-associated colon and rectal cancer: perinatal and cancer outcomes. J Matern Fetal Neonatal Med 2009; 22: 204-211.

3. Dalrymple JL, Gilbert WM, Leiserowitz GS et al. Pregnancy-associated cervical cancer: obstetric outcomes. J Matern Fetal Neonatal Med 2005; 17: 269-276.

4. Świerczewski A, Pasiński J, Estemberg D et al. Ciąża i poród u pacjentk z chłoniakiem nieziarniczym. Ginekol Pol. 2012; 83: 57-61.

5. Creasman WT. Cancer and pregnancy. Ann NY Acad Sci 2001; 943: 281-286.

6. Loibl S, Minckwitz G, Gwyn K et al. Breast carcinoma in pregnancy international recommendations from an expert meeting. Cancer 2006; 106: 237-46.

7. Krajowy Rejestr Nowotworów: http://onkologia.org.pl.

8. Smith LH, Danielsen B, Allen ME et al. Cancer associated with obstetric delivery: results of linkage with the California cancer registry. Am J Obstet Gynecol 2003; 189: 1128-1135.

9. Pavlidis NA. Coexistence of pregnancy and malignancy. Oncologist 2002; 7: 279-287.

10. Pentheroudakis G, Pavlidis N. Cancer and pregnancy: poena magna not anymore. Eur J Cancer 2006; 42: 126-140.

11. Hoellen F, Reibke R, Hornemann Ket al. Cancer in pregnancy. Part I: basic diagnostic and therapeutic principles and treatment of gynecological malignancies. Arch Gynecol Obstet 2012; 285: 195-205.

12. Van Calsteren $\mathrm{K}$, Heyns L, De Smet F et al. Cancer during pregnancy: an analysis of 215 patients emphasizing the obstetrical and the neonatal outcomes. J Clin Oncol 2010; 28: 683-689.

13. Jones WB, Shingleton HM, Russel A et al. Cervical carcinoma in pregnancy. A national patterns of care study of the American Colege of Surgeons. Cancer 1996; 77: 1479-1488.

14. Munkarah AR, Morris R. Malignant disease in pregnancy. In: High risk pregnancy: a management options. 2nd ed. James DK, Steer PJ, Weiner CP et al. (eds.). London: W.B. Saunders; 1994; 945-958.

15. Nguyen C, Montz FJ, Bristow RE. Management of stage I cervical cancer in pregnancy. Obstet Gynecol Surv 2000; 55: 633-643.

16. Method MW, Brost BC. Management of cervical cancer in pregnancy. Semin Surg Oncol 1999; 16: 251-260.

17. Germann N, Haie-Meder C, Morice P et al. Management and clinical outcomes of pregnant patients with invasive cervical cancer. Ann Oncol 2005; 16: 397-402.

18. Sood AK, Sorosky Jl, Krogman S et al. Surgical management of cervical cancer complicating pregnancy: a case-control study. Gynecol Oncol 1996; 63: 294-298.

19. Mocarska A, Starosławska E, Kieszko D et al. Rola rezonansu magnetycznego w ocenie stopnia zaawansowania raka szyjki macicy. Ginekol Pol 2012; 83: 122-127. 
20. Balleyguier C, Fournet C, Ben Hassen W et al. Management of cervical cancer detected during pregnancy: role of magnetic resonanse imaging. Clin Imaging 2013; 37: 70-76.

21. Germann N, Haie-Meder C, Morice $P$ et al. Management and clinical outcomes of pregnant patients with invasive cervical cancer. Ann Oncol 2005; 16: 397-402.

22. Bręborowicz G, KędziaW. Nowotwory u kobiet w ciąży. In:Zarys ginekologii onkologicznej. Markowska J, Mądry R (eds.). Poznań, 2012; 579-591.

23. American Brachytherapy Society: https://www.americanbrachytherapy.org.

24. Krebs L, Maillard S, Gaillot-Petit N et al. Total radiation dose and overall treatment time are predicitive for tumor sterliziation in cervical carcinoma treated with chemoradiation and pulsed-dose-rate brachytherapy. Brachytherapy 2015; 14: 16-22.
25. Baltazer J, Regenbrecht ME, Kopcke $W$ et al. Carcinoma of the cervix and pregnancy. Int J Gynaecol Obstet 1990; 31: 317-323.

26. Creasman WT, Rutledge FN, Fletcher GH. Carcinoma of the cervix associated with pregnancy. Obstet Gynecol 1970; 36: 495-501.

27. Hopkins MP, Morley GW. The prognosis and management of cervical cancer associated with pregnancy. Obstet Gynecol 1992; 80: 9-13.

28. Jones WB, Shingleton HM, Russell A et al. Cervical carcinoma and pregnancy. A national patterns of care study of the American College of Surgeons. Cancer 1996; 77: 1479-1488.

29. Lee RB, Neglia W, Park RC. Cervical carcinoma in pregnancy. Obstet Gynecol 1981; 58: 584-589.

30. Manuel-Limson GA, Ladines-Ilave CA, Sotto LS et al. Cancer of the cervix in pregnancy: a 31-year experience at the Philippine General Hospital. J Obstet Gynaecol Res 1997; 23: 503-509. 